\title{
How Much Will It Cost To Monitor Microbial Drinking Water Quality in Sub-Saharan Africa?
}

\author{
Caroline Delaire, ${ }^{*}{ }^{\dagger \odot}$ Rachel Peletz, $^{\dagger \odot}$ Emily Kumpel $^{\dagger \odot}{ }^{\dagger}$ Joyce Kisiangani, $^{\dagger}$ Robert Bain, ${ }^{\dagger}$ \\ and Ranjiv Khush ${ }^{\S}$ \\ †The Aquaya Institute, PO Box 21862, Nairobi, Kenya \\ ${ }^{\ddagger}$ Division of Data, Research and Policy, UNICEF, 3 UN Plaza, New York, New York 10017, United States

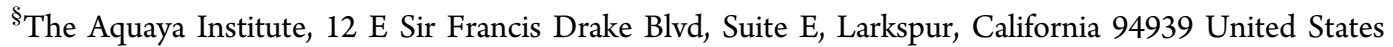

\section{Supporting Information}

ABSTRACT: Microbial water quality monitoring is crucial for managing water resources and protecting public health. However, institutional testing activities in sub-Saharan Africa are currently limited. Because the economics of water quality testing are poorly understood, the extent to which cost may be a barrier to monitoring in different settings is unclear. This study used cost data from 18 African monitoring institutions (piped water suppliers and health surveillance agencies in six countries) and estimates of water supply type coverage from 15 countries to assess the annual financial requirements for microbial water testing at both national and regional levels, using World Health Organization recommendations for sampling frequency. We found that a microbial water quality test costs $21.0 \pm 11.3$ USD, on average, including consumables, equipment, labor, and logistics, which is higher than previously calculated. Our annual cost estimates for microbial monitoring of piped supplies and improved point sources ranged between 8000 USD for Equatorial Guinea and 1.9 million USD for Ethiopia, depending primarily on the population served but also on the distribution of piped water system sizes. A comparison with current national water and sanitation budgets showed that the cost of implementing prescribed testing levels represents a relatively modest proportion of existing budgets (<2\%). At the regional level, we estimated that monitoring the microbial quality of all improved water sources in sub-Saharan Africa would cost 16.0 million USD per year, which is minimal in comparison to the projected annual capital costs of achieving Sustainable Development Goal 6.1 of safe water for all (14.8 billion USD).

\section{INTRODUCTION}

Exposure to fecally transmitted microbial pathogens is the primary global health risk associated with contaminated drinking water. ${ }^{1,2}$ Therefore, assessing microbial water quality is important for managing water resources and protecting public health. During the United Nation's Millennium Development Goal (MDG) period (2005-2015), the World Health Organization (WHO)-UNICEF Joint Monitoring Programme (JMP) for Water Supply and Sanitation relied on a proxy indicator for water supply safety: drinking water sources that were constructed or managed to minimize fecal contamination were classified as "improved" (piped water, protected groundwater, and rainwater) and vulnerable sources (unprotected groundwater and surface water) were classified as "unimproved". ${ }^{3}$ However, the limitations of this proxy are well recognized, as multiple studies have shown significant levels of fecal contamination in improved drinking water sources., ${ }^{4,5}$ Therefore, direct measurements of water quality are needed to assess water safety. More generally, water quality monitoring can allow water managers to identify contamination events, take corrective actions when needed, and close high-risk water sources. ${ }^{5}$ Water quality monitoring thus constitutes a crucial tool for water safety management.

In most countries, institutional responsibilities for water quality monitoring are established by national regulations or guidelines. These responsibilities generally fall into two categories: (1) operational monitoring (or water quality control) by water suppliers; and (2) surveillance (or compliance) monitoring by an independent agency, usually responsible for public health. ${ }^{6}$ However, in sub-Saharan Africa, actual testing levels by these institutions often fail to meet regulatory requirements, ${ }^{7}$ potentially due to institutional, personnel, and economic constraints. ${ }^{8}$ To strengthen testing programs, capacity building efforts generally include laboratory development and staff trainings. ${ }^{9}$ There is also increasing

Received: December 19, 2016

Revised: April 4, 2017

Accepted: May 1, 2017

Published: May 1, 2017 


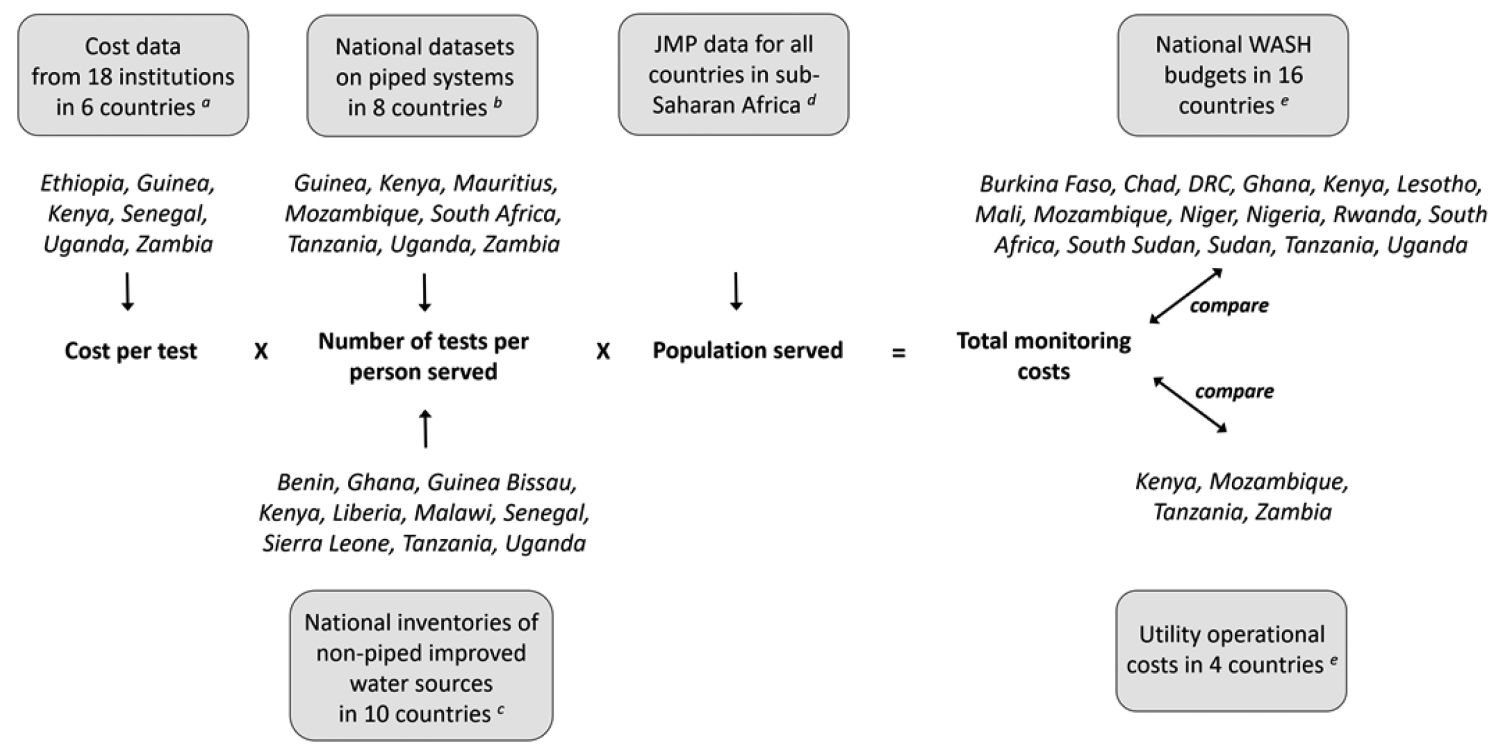

Figure 1. Overview of our approach to estimate and discuss the costs of microbial water quality monitoring in sub-Saharan Africa. The six countries chosen for the per-test cost estimate were the countries enrolled in the MfSW program. The other countries mentioned in the Figure were selected based on the availability of data. ${ }^{a}$ SI Table S5 and Figure 2. ${ }^{\mathrm{b}}$ Table $1 .{ }^{\mathrm{c}}$ Table 2. ${ }^{\mathrm{d}} \mathrm{SI}$ Table S2. ${ }^{\mathrm{e}}$ Table 3.

interest among public health practitioners, researchers, development agencies, and the WHO-UNICEF JMP in the development of low-cost water quality testing methods. ${ }^{10-12}$ These efforts suggest that financial constraints are typically assumed to be the main barrier to testing. However, the economics of water quality testing remain poorly understood and the costs of water quality monitoring at national levels have never been assessed. Therefore, the extent to which cost may be an actual barrier to monitoring in different settings is unclear.

Conducting a microbial water quality test involves four types of expenses: consumables, laboratory equipment, labor (for collecting and analyzing samples), and logistics (transport and communication). Two previous studies have provided partial estimates of microbial testing costs. ${ }^{13,14}$ Bain et al. collected information from manufacturers on the costs of consumables for 44 microbial testing methods (categorized into presence/ absence, most probable number (MPN), and colony counts). ${ }^{13}$ They found that the costs per test ranged between 0.5 and 7.5 USD (the cost of specialized laboratory equipment was reported separately). These estimates, however, did not include the cost of labor and logistics. In another study, Crocker et al. relied on interviews and observations in laboratories and treatment plants in seven countries to estimate the marginal costs of testing (consumables, labor, and sample transport). ${ }^{14}$ For the two sub-Saharan African countries in their analysis (South Africa and Uganda), they found an average marginal cost per test of 8.4 USD, which also excluded ancillary equipment costs. Both studies relied on consumables cost data provided by manufacturers, which are likely lower than the actual costs of acquiring supplies in Africa after shipping and importation taxes. Consequently, the real cost of a microbial water quality test in sub-Saharan Africa remains unknown.

In this study, we asked four questions:

(1) What is the actual cost of one microbial water quality test in sub-Saharan Africa, including consumables, equipment, labor, and logistics?

(2) How does the per-test cost and its composition vary between and within countries?
(3) How much will it cost to monitor microbial water quality according to WHO recommendations for all improved drinking water sources in sub-Saharan Africa? and

(4) How does this cost compare to Water, Sanitation and Hygiene (WASH) budgets?

To answer these questions, we used actual cost data from 18 African monitoring institutions to propose a revised cost-pertest estimate. This study is also the first, to our knowledge, to systematically estimate the number of microbial tests required at national levels. These two types of estimates then allowed us to assess the annual financial requirements for microbial water testing at national and regional levels (46 countries total).

We focused our analysis on improved water sources because previous analyses of microbial water quality in Africa show that improved sources have variable levels of contamination. ${ }^{5}$ In contrast, unimproved sources are highly likely to contain microbial contamination, and, therefore, should be considered unsafe for consumption without treatment. Our results provide a nuanced understanding of the economics of microbial water quality monitoring and can guide the allocation of resources to improve water safety management in sub-Saharan Africa.

\section{MATERIALS AND METHODS}

As described below, we used multiple sources of data from different countries to estimate the cost of a microbial test, the population served by improved water sources, and the number of tests required per person served. For the latter, we started with countries from which data were available (listed in Figure 1) and then extrapolated to the other countries in sub-Saharan Africa (46 countries total). These data allowed us to calculate the total monitoring costs at both national and regional levels. The monitoring costs were then compared to national WASH budgets and utility operational costs. Our approach is summarized in Figure 1.

2.1. Cost of a Microbial Test in Sub-Saharan Africa. We classified the costs of a microbial water quality test into four categories: equipment, consumables, labor, and logistics. Equipment included the costs of durable and reusable laboratory items such as field kits, incubators, autoclaves, 
Table 1. Annual Number of Tests Per Individual Served with Piped Water in Eight Countries, and Estimated Annual Costs (USD) of Microbial Water Quality Monitoring (Using an Average Cost Per Test of 21.0 USD)

\begin{tabular}{|c|c|c|c|c|c|c|}
\hline \multirow[b]{2}{*}{ country } & \multirow[b]{2}{*}{$\begin{array}{c}\text { population served with piped } \\
\text { water }^{a}\end{array}$} & \multirow[b]{2}{*}{$\begin{array}{c}\text { number of water } \\
\text { systems }\end{array}$} & \multicolumn{2}{|c|}{$\begin{array}{l}\text { annual number of } \\
\text { microbial water quality } \\
\text { tests }\end{array}$} & \multirow[b]{2}{*}{$\begin{array}{c}\text { annual costs of microbial water quality } \\
\text { monitoring (USD) }\end{array}$} & \multirow[b]{2}{*}{$\begin{array}{c}\text { data } \\
\text { source }\end{array}$} \\
\hline & & & total & $\begin{array}{l}\text { per } 1000 \\
\text { people }\end{array}$ & & \\
\hline Guinea & 4252781 & 132 & 7836 & 1.84 & 164556 & 30,31 \\
\hline Kenya & 16126525 & 1297 & 33072 & 2.05 & 694512 & $32-35$ \\
\hline Mauritius & 1248383 & 6 & 2256 & 1.81 & 47376 & 36 \\
\hline Mozambique & 7438753 & 180 & 14652 & 1.97 & 307692 & 37,38 \\
\hline South Africa & 47545546 & 1036 & 78252 & 1.65 & 1643292 & 39 \\
\hline Tanzania & 13379723 & 937 & 25524 & 1.91 & 536004 & 40 \\
\hline Uganda & 8271443 & 1,312 & 23868 & 2.89 & 501228 & 41 \\
\hline Zambia & 5232697 & 17 & 6108 & 1.17 & 128268 & 42 \\
\hline
\end{tabular}

${ }^{a}$ As estimated by JMP (piped on premises + public taps), except for Guinea, South Africa, and Zambia, for which we used the population estimates by the national supplier or regulator, which were higher than JMP's. ${ }^{b}$ Detailed derivations for the number of utilities are presented in SI Text S2.

refrigerators, weighing scales, hot plates, magnetic stirrers, glassware, culture tube racks, inoculation loops, pipettes, and UV lamps. Consumables included the costs of reagents and one-time use laboratory items such as alcohol disinfectant, distilled water, filter paper, absorbent pads, cotton swabs, gloves, and gas cylinders. Labor included salaries and/or per diem expenses for personnel involved in sample collection and microbial testing. Logistics included costs related to transportation and communication, such as vehicle rental or maintenance, fuel, fare for public transportation, airtime, and Internet credit.

We collected primary cost data from eight water suppliers and ten health surveillance agencies located in Ethiopia, Guinea, Kenya, Tanzania, Uganda, and Zambia. These institutions participated in The Aquaya Institute's Monitoring for Safe Water research program (MfSW), which has been described elsewhere. ${ }^{5,7}$ The 18 institutions were selected to capture the diversity of regulated monitoring organizations in sub-Saharan Africa, with respect to geographic settings (urban and rural), catchment areas (49 to $276227 \mathrm{~km}^{2}$ ), populations covered by monitoring activities (75 343 to 20000000 ), testing methods (membrane filtration, MPN, hydrogen sulfide presence/absence tests $\left(\mathrm{H}_{2} \mathrm{~S}\right)$, and Petrifilm-Colilert), monitoring program structures, and water sources (piped supplies, boreholes, dug wells, rainwater tanks, springs) (SI Table S1). ${ }^{5,7}$ The MfSW research protocol was evaluated and exempted from full review by the Western Institutional Review Board (WIRB) (Olympia, WA).

Between December 2014 and January 2015, we asked the 18 institutions to provide information on the costs they incurred during the MfSW program, by filling out an itemized form organized according to the four cost categories. Institutions only provided data for the items corresponding to their testing procedures. We then used a variety of methods to address gaps in cost data: receipts submitted to Aquaya as part of the MfSW program, cost estimates provided by local equipment suppliers, data collected during in-depth interviews between 2012 and 2014, and follow-up calls in 2016. We amortized equipment costs over their estimated lifespan (according to our field experience): 10 years for large static items such as incubators, autoclaves, weighing scales, etc.; five years for small and movable items such as test kits, pipets, UV lamps, etc.; and two years for glassware. Difficulties in reaching less accessible sampling locations are reflected in the logistics costs. All costs were standardized using currency exchange rates of January first, 2015, ${ }^{15}$ which corresponds to the period when institutions filled the itemized forms. Based on this information, we calculated the average cost per microbial test across the 18 institutions.

To estimate the additional costs of quality assurance procedures (replicates, positive and negative controls), we assumed that these procedures would result in a $10 \%$ increase in the number of samples (based on the minimum recommendations from Bartram and Balance, 1996), ${ }^{16}$ increasing the consumables and labor costs by $10 \%$. To obtain a rough approximation of physicochemical testing expenses $(\mathrm{pH}$, turbidity, and chlorine residual), we used equipment and consumables costs found in the literature and in a manufacturer's catalog. ${ }^{17}$ Details are provided in SI Text S1.

2.2. Population Using Piped and Nonpiped Improved Water Sources in Sub-Saharan Africa. We estimated the number of people using piped water (piped on premises and public standpipes) and improved point source water supplies (rainwater, boreholes/tubewells, protected dug wells, and protected springs) in each sub-Saharan African country. To make these estimates, we first used the JMP's most recent data sets ${ }^{18}$ to identify the percentages of rural and urban populations in each sub-Saharan African country that relied on piped water and improved point sources. We then multiplied these percentages by 2015 rural and urban population estimates from the UN Population Division ${ }^{18}$ to obtain the number of people using piped water or improved point sources in each country (SI Table S2).

2.3. Number of Tests Required Per Person Served by Piped Water. The WHO Guidelines for Drinking Water Quality recommendations for microbial water quality monitoring, which inform most national standards, are presented in SI Table S3. ${ }^{19}$ With respect to piped supplies, the recommended amount of testing depends on the size of the population served by each system. Therefore, we first estimated the number and size of piped water systems in eight countries (Guinea, Kenya, Mauritius, Mozambique, South Africa, Tanzania, Uganda, and Zambia). These countries were selected because data from national suppliers, regulators, or ministries were either publicly available or could be obtained through the MfSW program (Table 1). In Kenya, Mozambique, Tanzania, and Uganda, the populations served by piped supplies, as estimated from local data sources, were lower than the JMP estimates, suggesting that a number of water systems, likely unregulated, were missing from the official databases. We assumed these "missing" 
Table 2. Average Number of Users Per Improved Point Water Source in 10 Countries, And Estimated Annual Costs (USD) of Microbial Water Quality Monitoring (Using an Average Cost Per Test of 21.0 USD)

\begin{tabular}{|c|c|c|c|c|c|c|}
\hline country & $\begin{array}{l}\text { population served with } \\
\text { improved point water } \\
\text { sources }{ }^{a}\end{array}$ & $\begin{array}{l}\text { number of functional } \\
\text { improved point water } \\
\text { sources }\end{array}$ & $\begin{array}{l}\text { annual number of } \\
\text { water quality tests }\end{array}$ & $\begin{array}{l}\text { average number of } \\
\text { users per point source }\end{array}$ & $\begin{array}{l}\text { annual costs of microbial water } \\
\text { quality monitoring (USD) }\end{array}$ & $\begin{array}{l}\text { data } \\
\text { source }\end{array}$ \\
\hline Benin $^{b}$ & 2256205 & 5270 & 1318 & 428 & 27668 & 43 \\
\hline Ghana & 11105696 & 26890 & 6723 & 413 & 141173 & 44 \\
\hline $\begin{array}{l}\text { Guinea } \\
\text { Bissau }\end{array}$ & 357771 & 5644 & 1411 & 63 & 29631 & 45 \\
\hline Kenya $^{c}$ & 1334781 & 3497 & 874 & 382 & 18359 & 35,46 \\
\hline Liberia & 2984534 & 6893 & 1723 & 433 & 36188 & 47 \\
\hline Malawi $^{b}$ & 10898170 & 43574 & 10894 & 250 & 228764 & 48 \\
\hline Senegal $^{b}$ & 1270387 & 3288 & 822 & 386 & 17262 & 49 \\
\hline $\begin{array}{l}\text { Sierra } \\
\text { Leone }\end{array}$ & 2451589 & 14666 & 3667 & 167 & 76997 & 50 \\
\hline Tanzania $^{b}$ & 22745039 & 42591 & 10648 & 534 & 223602 & 51 \\
\hline Uganda & 20917384 & 84755 & 21189 & 247 & 444964 & 41 \\
\hline average & & & & 330 & & \\
\hline
\end{tabular}

${ }^{a}$ JMP estimates, except for Kenya, Senegal, and Uganda, whose water point inventories provided estimates of population served. ${ }^{b}$ Rural areas only. ${ }^{c}$ Only five counties within Kenya (Busia, Embu, Isiolo, Kajiado, and Kisumu).

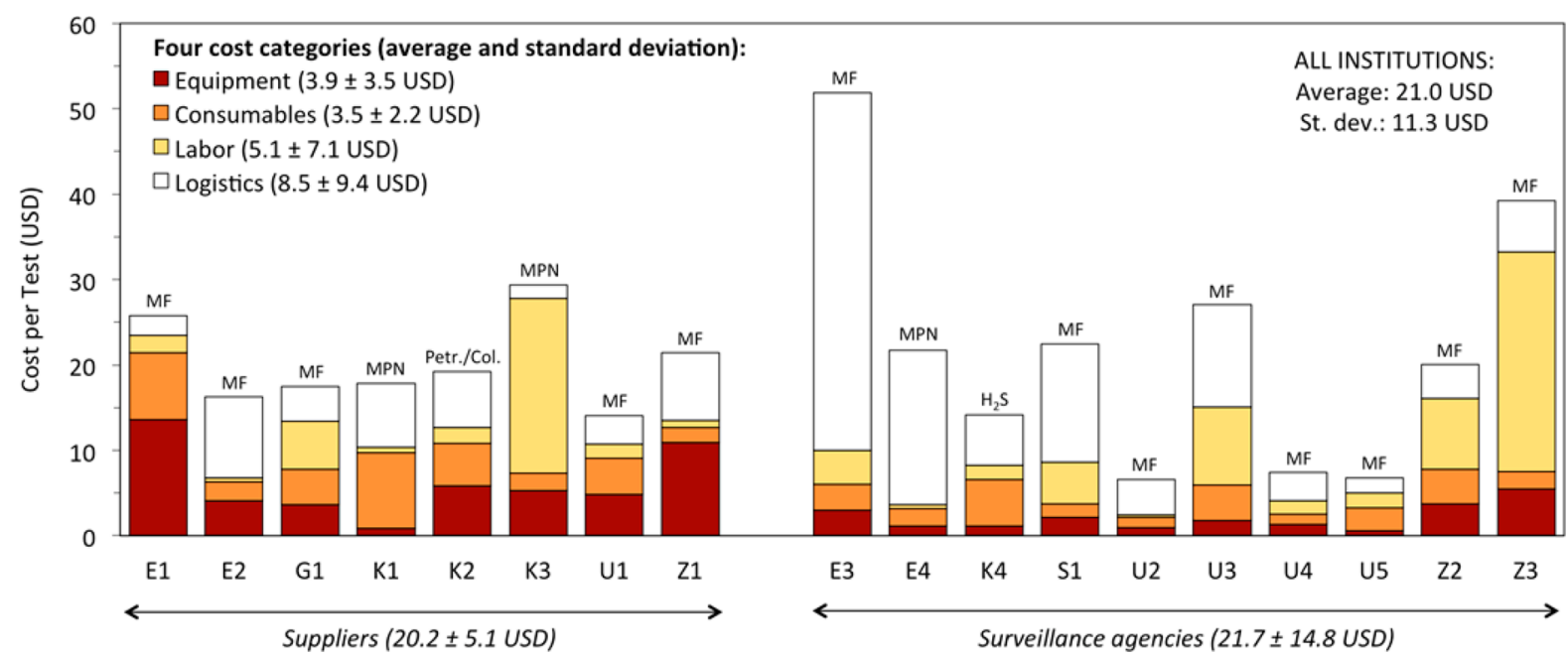

Figure 2. Cost (USD) of one microbial water quality test in $18 \mathrm{MfSW}$ partner institutions in categories of equipment, consumables, labor, and logistics. The currency exchange rate of $1 / 1 / 2015$ was used. Institutions have been anonymized, but the countries (Ethiopia, Guinea, Kenya, Senegal, Uganda, and Zambia) are represented by their first letter. The testing method used by each institution is indicated. Specific costs for each institution are detailed in SI Table S5.

systems to be small (serving $<10000$ people). A detailed derivation of the number and size of piped water systems in each of the eight countries is given in SI Text S2. A quantitative summary of this analysis, broken down by water system size, is shown in SI Figure S1.

For each of the eight countries, we used WHO monitoring recommendations (SI Table S3) and our estimates of piped system sizes to calculate the annual number of microbial water quality tests required per country and per individual served by piped water (per capita). Using these results, we then derived a model to predict the annual number of tests per capita. We hypothesized that this number was related to the proportion of a country's population that is rural and/or to the level of piped water coverage (SI Table S2) since these can affect the size of water systems. We thus tested several linear models using one or two variables - \% rural, \% coverage of piped water (from SI Table S2) - including with an interaction term between the two variables. The $R^{2}$ goodness-of-fit values for the four models tested are listed in SI Table S4. We then used the best model (highest $R^{2}$ value) to estimate the annual number of tests per capita for each country in sub-Saharan Africa.

2.4. Number of Tests Required Per Person Served by Improved Point Sources. The WHO Guidelines recommend testing all point source water supplies every 3-5 years (SI Table S3). Therefore, calculating the recommended number of tests per country-and per capita-required an estimate of the total number of point sources. We identified publicly available water point inventories (generated through organized mapping efforts to record all water sources) for 10 countries: Benin, Ghana, Guinea Bissau, Kenya, Liberia, Malawi, Senegal, Sierra Leone, Tanzania, and Uganda (Table 2). For each of these ten countries, we calculated the average number of users per improved point source. When information on population served was not available from the inventories, we used JMP estimates (SI Table S2). Assuming that every source should be tested every four years (the WHO Guidelines recommend every 3-5 years), we converted the average number of users per source across the ten countries into an annual number of 
tests per capita, which we then applied to every country in subSaharan Africa.

2.5. Costs of Monitoring All Improved Water Sources in Sub-Saharan Africa. For each country in sub-Saharan Africa, and for each type of improved water source (piped and nonpiped), we multiplied the estimated annual number of tests per capita (from sections 2.3 and 2.4) by the population served (SI Table S2) to calculate the number of tests required per country. We then estimated the corresponding costs using the average cost per microbial test calculated in section 2.1.We also performed sensitivity analyses using (i) the 5th and 95th percentiles of the numbers of tests per capita in the eight initial countries for piped supplies and (ii) the fifth and 95th percentiles of the numbers of users per source in the ten initial countries for improved point sources.

Finally, we compared the costs of monitoring all improved water sources with national WASH budgets reported in the 2014 GLAAS report by UN Water ${ }^{20}$ (available for 16 countries). We also compared our estimated monitoring costs with utility operational costs reported by regulators and national providers (available for the largest utilities in four countries).

\section{RESULTS}

3.1. Cost of a Microbial Water Quality Test in SubSaharan Africa. The average cost of conducting one microbial test across the 18 institutions was $21.0 \pm 11.3$ USD (Figure 2 and SI Table S5). Upfront equipment capital costs varied between 4200 USD and 41700 USD (with an average of 17700 USD, data not shown), reflecting differences in institution sizes, testing methods, monitoring typologies, and costs of procuring equipment in country (amortized equipment costs are also included in the per-test cost). Per-test costs were more variable among health surveillance agencies than among suppliers (relative standard deviations of $68 \%$ and $25 \%$, respectively) (Figure 2 and SI Table S5). Equipment costs were significantly higher for suppliers than for surveillance agencies ( $+188 \%, p<0.05, t$ test) (SI Table S5). Overall, average costs per test were highest in Ethiopia (28.9 \pm 15.8 USD) and Zambia (26.9 \pm 10.7 USD), and lowest in Uganda (12.4 $\pm 8.8 \mathrm{USD})$, but because of large intracountry variations, we found no statistically significant difference between countries (all $p>0.05, t$ test) (SI Table S5).

All 18 institutions brought samples to a laboratory for analysis rather than performing microbial tests in the field. Logistics costs were not significantly different between institutions using a single testing location $(n=12)$ and those using several $(n=6)$ (SI Tables S1 and S5) $(p>0.05, t$ test). After excluding logistical expenses (which do not depend on the testing method), the type of quantitative microbial test used by an institution did not appear to influence per-test costs: membrane filtration (12.5 \pm 8.1 USD, $n=13)$, MPN (14.0 \pm 12.4 USD, $n=3)$, and Petrifilm-Colilert ${ }^{21,22}(12.7$ USD, $n=1)$. However, per-test costs were lower for $\mathrm{H}_{2} \mathrm{~S}$ presence/absence tests (8.3 USD, $n=1)$ (SI Table S5).

Quality controls and replicates, which we estimated would increase the expenses for consumables and labor by $10 \%$, would result in an addition of 0.9 USD (+4\%) to the per-test cost. We also estimated that the equipment and consumables costs for physicochemical testing would amount to approximately 1.2 USD per test (SI Text S1). Assuming that physicochemical tests would be conducted in the field by the same staff collecting samples for microbial testing (negligible additional expenses for labor and logistics), conducting these tests would be equivalent to a $6 \%$ increase in the cost per test.

3.2. Annual Costs of Monitoring Piped Water Supplies in Sub-Saharan Africa. Our estimates of the number of piped water supplies in Guinea, Kenya, Mauritius, Mozambique, South Africa, Tanzania, Uganda, and Zambia showed substantial variation: from six in Mauritius to 1,312 in Uganda (Table 1). The size distribution of piped water systems was also diverse, with the majority of systems in Mauritius and Zambia serving over 100000 people, and the majority of systems in Guinea, Kenya, Uganda, and Tanzania serving fewer than 5000 people (SI Figure S1).

These differences in the sizes of piped water systems between countries resulted in substantial variation in the annual number of microbial water quality tests per capita. In Zambia, where most of the water systems are large, the number of annual tests per capita was the lowest (1.17 per 1000 people). In contrast, in Uganda, the large proportion of small water systems led to the highest number of annual tests per capita (2.89 per 1000 people).

The best model $\left(R^{2}=0.90\right)$ to predict the annual number of tests per capita is described by eq 1 , where \%rural and \% coverage are the proportions of a country's population living in rural areas and served by piped water, respectively (SI Table S4). A comparison between our estimated numbers of microbial tests per capita in the eight selected countries and the model prediction is shown in Figure 3.

$$
\begin{aligned}
& \frac{\text { annual number of tests }}{1000 \text { people served by piped water }} \\
& =-3.46+0.08 \times \% \text { rural }+0.06 * \% \text { coverage } \\
& \quad-0.0009 \times \% \text { rural } \times \% \text { coverage }
\end{aligned}
$$

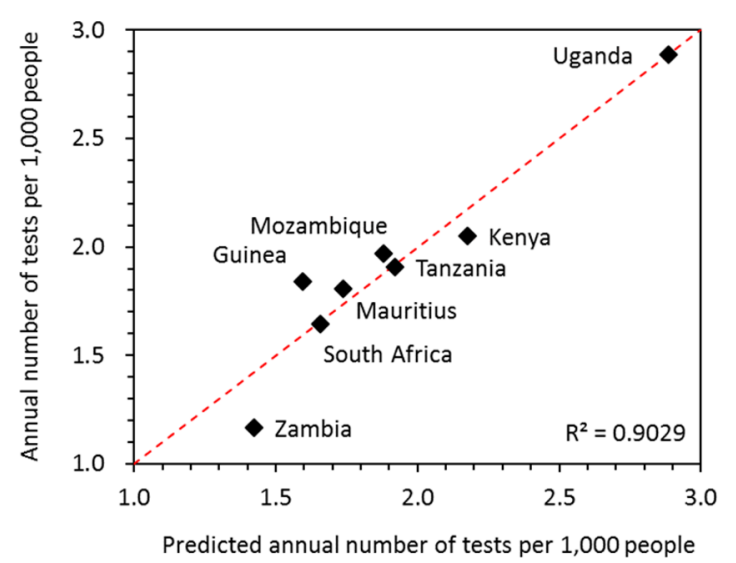

Figure 3. Annual number of tests per 1000 people served with piped water in eight countries (black diamonds, Table 1) compared to the best model prediction (dashed line, $R^{2}=0.902$, eq 1 ), which is based on \% rural (UN Population Division estimates) and \% coverage of piped water (JMP estimates) (SI Table S2).

Using this model, we estimated the costs of monitoring piped water supplies, based on WHO recommendations, for all countries in sub-Saharan Africa. These costs varied between 1403 USD for Liberia and 1655672 USD for South Africa, and amounted to 10931000 USD for the entire region (Figure 4a and SI Table S6). Monitoring costs for piped supplies did not increase linearly with the population served (Figure 4a), because the number of tests per capita varied between countries 
a)

Piped water monitoring costs (USD/year)

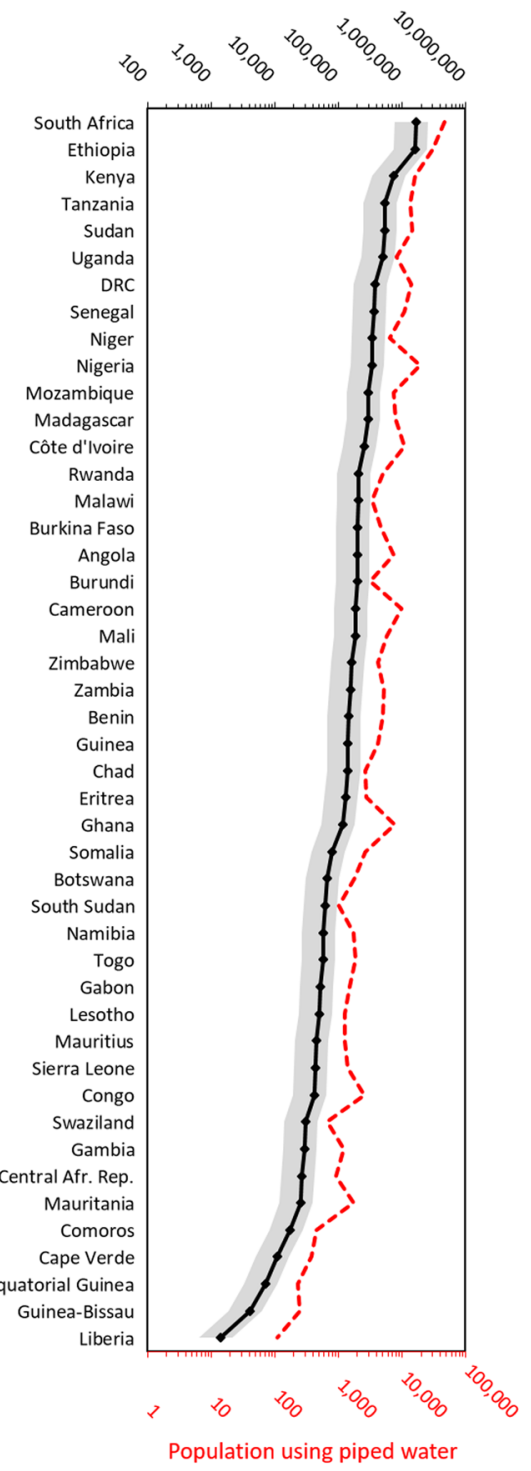

b)

Monitoring costs of improved point sources (USD/year)

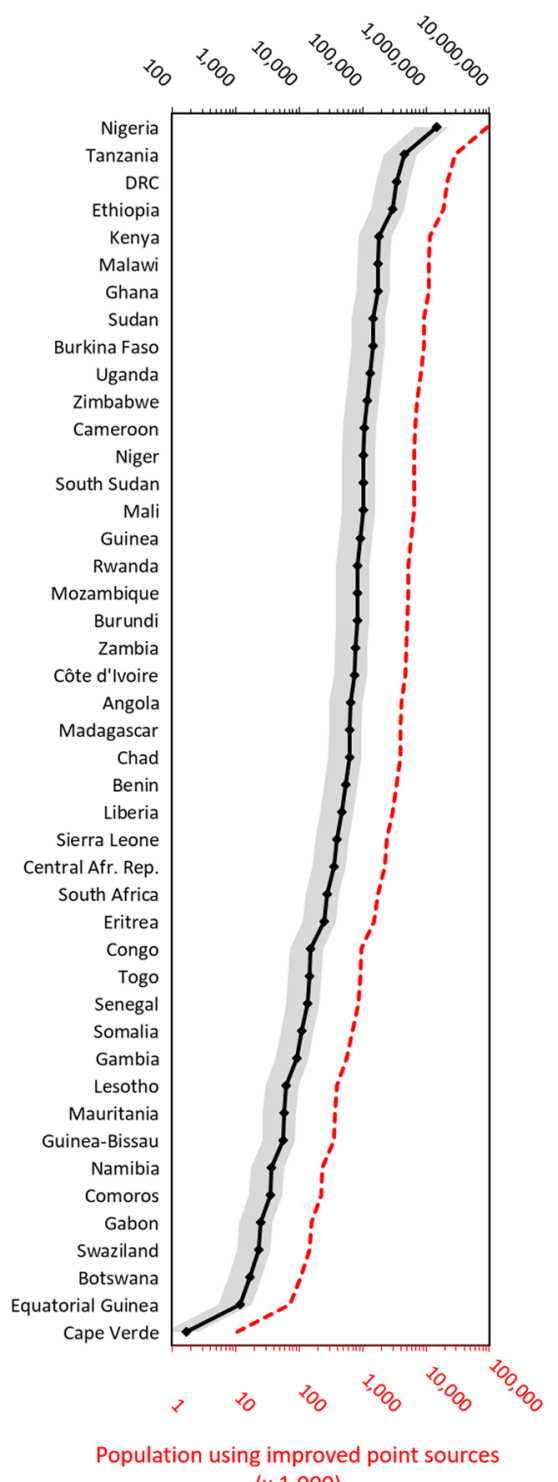

C) Total water monitoring costs (USD/year)

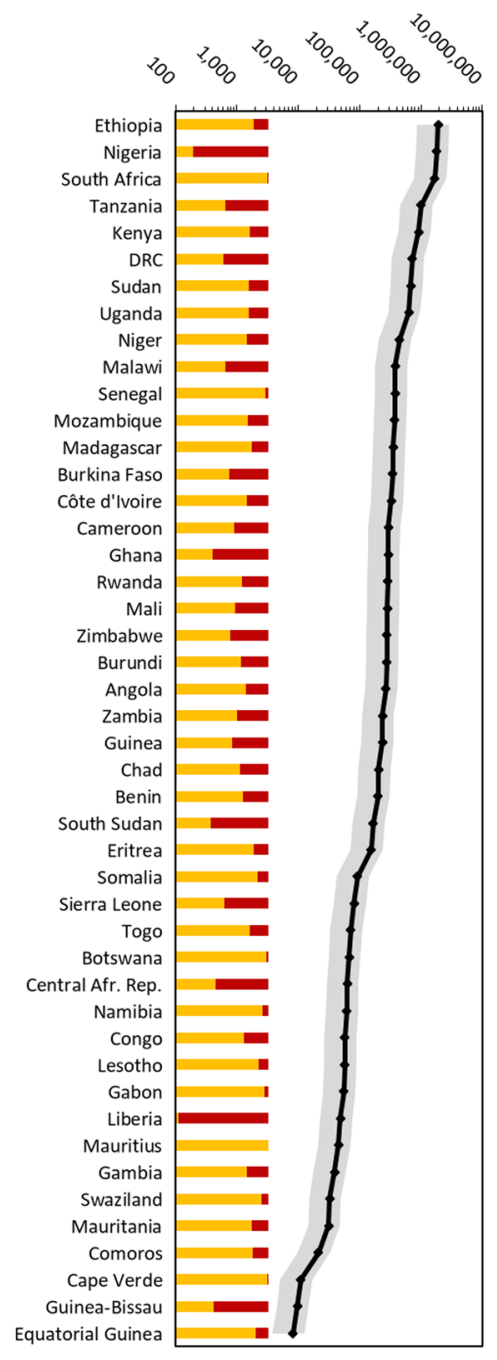

$(x 1,000)$

Figure 4. Estimated annual costs (USD) of microbial water quality monitoring in all sub-Saharan African countries, for piped water (panel a), improved point sources (panel b), and both (panel c). On panel c, the bars indicate the respective fractions of the total costs corresponding to piped supplies and improved point sources. On panels $a$ and $b$, the population using piped water and improved point sources, respectively, according to JMP's 2015 estimates, is indicated. The estimated costs of microbial water quality monitoring in sub-Saharan Africa amount to 10931000 USD for piped water, 5106000 USD for improved point sources, and 16038000 USD overall.

as a function of the estimated size of water systems. Our sensitivity analysis yielded cost estimates of 8458782 and 16435000 USD per year, respectively (SI Table S6).

\subsection{Annual Costs of Monitoring Improved Point} Sources in Sub-Saharan Africa. Our estimates for the average number of users per improved point water source ranged from 63 in Guinea Bissau to 534 in Tanzania. We note that our estimated average number of users per water point, 330 , is higher than the 250 users recommended by UNICEF for shared sources such as handpumps and public standpoints. ${ }^{23}$

Assuming 330 users per water point, we estimated that the annual monitoring costs for all improved point sources in subSaharan Africa amount to 5106000 USD (Figure 4b, SI Table S6). Monitoring costs increased linearly with the population served (Figure 4b), because we used a uniform number of users per water point, and therefore a uniform number of tests per capita across countries ( 0.76 annual tests per 1,000 people). Our sensitivity analysis yielded lower and upper bounds of 3449000 USD and 15347000 USD, respectively (SI Table S6).

3.4. Annual Costs of Microbial Water Quality Monitoring in Sub-Saharan Africa. Combining our cost estimates for monitoring piped water supplies and improved point sources resulted in an annual cost estimate for microbial water quality monitoring in sub-Saharan Africa of 16038000 USD (Figure 4c and SI Table S6). The five countries with the highest estimated microbial monitoring costs were Ethiopia, Nigeria, South Africa, Tanzania, and Kenya (Figure 4c). Except for six countries (Central African Republic, Guinea Bissau, Ghana, Liberia, Nigeria, and South Sudan), piped supplies 
Table 3. Comparison of the Estimated Annual Costs of Microbial Water Quality Monitoring with (i) National Annual WASH Budgets (16 Countries) and (ii) Annual Operational Costs of the Largest Utilities (Four Countries)

\begin{tabular}{|c|c|c|c|c|c|c|c|}
\hline \multirow[b]{2}{*}{ country } & \multicolumn{3}{|c|}{ national level } & \multicolumn{4}{|c|}{ utility level $^{b}$} \\
\hline & $\begin{array}{l}\text { estimated annual microbial } \\
\text { water quality monitoring } \\
\operatorname{costs}^{a} \text { (million USD) }\end{array}$ & $\begin{array}{l}\text { reported annual } \\
\text { national budget for } \\
\text { WASH (million } \\
\text { USD) }\end{array}$ & $\begin{array}{l}\% \text { of } \\
\text { WASH } \\
\text { budget }\end{array}$ & $\begin{array}{l}\text { number of } \\
\text { utilities in } \\
\text { this estimate }\end{array}$ & $\begin{array}{l}\text { estimated annual microbial } \\
\text { water quality monitoring } \\
\operatorname{costs}^{b} \text { (million USD) }\end{array}$ & $\begin{array}{l}\text { reported annual } \\
\text { operational costs } \\
(\text { million } \\
\text { USD })^{32,37,40,42}\end{array}$ & $\begin{array}{l}\% \text { of utility } \\
\text { operational } \\
\text { costs }\end{array}$ \\
\hline South Africa & 1.67 & 3991 & $0.04 \%$ & & & & \\
\hline DRC & 0.73 & 1081 & $0.07 \%$ & & & & \\
\hline Nigeria & 1.82 & 587 & $0.31 \%$ & & & & \\
\hline Kenya & 0.88 & 300 & $0.29 \%$ & 91 & 0.35 & 175 & $0.20 \%$ \\
\hline Ghana & 0.29 & 263 & $0.11 \%$ & & & & \\
\hline Mozambique & 0.39 & 259 & $0.15 \%$ & 16 & 0.11 & 61 & $0.18 \%$ \\
\hline Tanzania & 1.00 & 86 & $1.17 \%$ & 33 & 0.22 & 95 & $0.23 \%$ \\
\hline Uganda & 0.63 & 84 & $0.75 \%$ & & & & \\
\hline Mali & 0.29 & 79 & $0.36 \%$ & & & & \\
\hline Niger & 0.45 & 69 & $0.65 \%$ & & & & \\
\hline Burkina Faso & 0.35 & 52 & $0.67 \%$ & & & & \\
\hline Chad & 0.20 & 47 & $0.44 \%$ & & & & \\
\hline Sudan & 0.69 & 41 & $1.68 \%$ & & & & \\
\hline Rwanda & 0.29 & 36 & $0.81 \%$ & & & & \\
\hline South Sudan & 0.17 & 33 & $0.50 \%$ & & & & \\
\hline Lesotho & 0.06 & 26 & $0.22 \%$ & & & & \\
\hline Zambia & & & & 11 & 0.12 & 97 & $0.13 \%$ \\
\hline average & & & $0.51 \%$ & & & & $0.19 \%$ \\
\hline
\end{tabular}

${ }^{a}$ For all improved water sources. ${ }^{b}$ For the piped systems managed by these utilities. ${ }^{c}$ For Kenya, we used utility revenue as opposed to operational costs.

accounted for the majority of microbial monitoring costs (Figure 4c). Overall, point sources represented 32\% of monitoring costs.

Table 3 compares our cost estimates for monitoring all improved sources with national WASH budgets in 16 countries, and shows that annual microbial monitoring costs correspond to between $0.04 \%$ and $1.68 \%$ of total government allocations to water and sanitation (with an average of $0.51 \%$ ). When comparing monitoring costs with utility operational costs for large piped water systems in Kenya, Mozambique, Tanzania, and Zambia, we found that monitoring costs correspond on average to $0.1-0.2 \%$ of their operational costs (Table 3 ).

\section{DISCUSSION}

4.1. Representativeness of the Cost-Per-Test Estimate. We found that on average the cost of conducting a microbial water quality test in sub-Saharan Africa was $21.0 \pm$ 11.3 USD. We derived this estimate from the actual expenditures of 18 water suppliers and surveillance agencies in six countries capturing a diversity of geographic settings, catchment areas, populations covered by monitoring activities, testing methods, monitoring program structures, and water sources (SI Table S1). The cost per test was highly variable between institutions, likely reflecting a combination of countrylevel (e.g., importation taxes, fuel prices) and institution-level (e.g., testing method, geographic area covered, procurement procedures) differences.

With respect to consumables, the costs that we calculated were higher than previous estimates by Bain et al. for membrane filtration (by 1.5 USD, i.e., $+93 \%$ ) and for $\mathrm{H}_{2} \mathrm{~S}$ presence/absence tests (by 4.2 USD, i.e., $+324 \%$ ), but similar for MPN and Petrifilm-Colilert tests $(<0.1$ USD, i.e., 3\%, difference). ${ }^{13}$ On average, our cost estimate for consumables $(3.5 \pm 2.2$ USD) was substantially higher $(+108 \%)$ than calculated by Crocker et al. (1.7 USD). ${ }^{14}$ Our finding of higher consumables costs likely reflects importation and delivery expenses, which were not included in the previous analyses. ${ }^{13,14}$ We also included peripheral consumables such as distilled water, alcohol, and gloves in our calculations, whereas previous studies only considered expenses related to growth media and membrane filters, which may further explain the discrepancy between our estimates.

Our estimated cost per microbial test $(21.0 \pm 11.3$ USD $)$ in Africa was also significantly higher than previously estimated by Crocker et al. (7.3 USD for low- and middle-income countries in general, and 8.4 USD for South Africa and Uganda). ${ }^{14}$ Although their analysis only accounted for marginal costs (consumables, labor, and logistics), our addition of equipment costs (3.9 \pm 3.5 USD) does not, by itself, account for the differences between the two studies: in addition to higher consumables costs, we found labor and logistics costs to be $84 \%$ and $201 \%$ higher, respectively, than previously estimated. ${ }^{14}$ The higher logistics costs may result from higher local transportation prices and/or longer travel times due to distant sampling areas or poor road infrastructure. For example, the MfSW partner institution with the highest logistics costs (E3, 41.9 USD per test) (Figure 2) had to travel up to $300 \mathrm{~km}$ to reach sampling points. Similarly, Wright et al. found that sample transportation for water quality monitoring can take over $6 \mathrm{~h}$ in Colombia, ${ }^{24}$ which is less rural than many subSaharan African countries. ${ }^{25}$

Our analysis shows that equipment and consumables represent only a fraction (35\% on average, SI Table S5) of the total per-test cost. Therefore, labor and logistics should be taken into account when selecting testing methods and allocating resources to monitoring. Finally, large variations within groups of institutions (e.g., surveillance agencies in Uganda and Zambia, Figure 2) suggest that there is potential to 
reduce costs through the sharing of testing practices between institutions.

4.2. Affordability of Water Quality Monitoring. Our results indicate that the costs of monitoring the microbial water quality of all improved sources in sub-Saharan Africa, 16038000 USD per year, are relatively modest. Specifically, this estimate is small compared to annual aid commitments to sub-Saharan Africa for water and sanitation (4 billion USD in 2012). ${ }^{20}$ It is also minimal compared to the estimated annual capital costs of achieving SDGs 6.1 in sub-Saharan Africa (14.8 billion USD). ${ }^{26}$ More significantly, for at least 16 countries, microbial monitoring costs correspond to less than $2 \%$ of their current national budgets for water and sanitation (Table 3 ). For Ethiopia and Tanzania, which are among the five countries with the highest estimated monitoring costs (Figure 4c), these costs correspond to only $1.1 \%$ and $0.5 \%$ of annual aid disbursements for WASH. ${ }^{20}$ For large utilities, the costs of implementing WHO recommendations for monitoring the microbial quality of piped supplies represent $<0.5 \%$ of current operational costs (Table 3). Furthermore, monitoring costs remain relatively modest even when taking into account quality controls and physicochemical testing, which we estimated would only result in a $10 \%$ increase in costs. Finally, our analysis focused on estimating the total costs of monitoring improved water sources. Since some monitoring is already taking place, ${ }^{7}$ the additional expenses required to reach the testing frequency recommended by $\mathrm{WHO}$, at least in some countries, may be lower than we estimated.

Nevertheless, though microbial water quality monitoring appears affordable at national levels, testing costs may be prohibitive for individual institutions with limited revenues or resources. For example, small piped systems, which often have lower revenues per capita than large suppliers, have to conduct more tests per capita (SI Table S3). Small systems also represent a large fraction of the overall testing requirements ( $21 \%$ across the eight countries in Table 1, see SI Figure S1). Similarly, surveillance agencies that operate in vast rural areas and face prohibitive logistical costs generally lack the investment capacity for building additional field laboratories (which would decrease their transportation costs). These challenges may partially explain why small piped systems and point sources are less likely to meet microbial monitoring requirements than large piped systems in sub-Saharan Africa. Therefore, options to improve the cost-effectiveness of monitoring in lower capacity systems need to be investigated, for example through a combination of physicochemical proxies (turbidity, chlorine residual) and lower-cost microbial tests.

It is also important to consider the upfront investment required for initiating a monitoring program. These start-up costs can include physical infrastructure (a building with reliable electricity and water), laboratory equipment, staff training, and water point mapping. Across the MfSW participants, we calculated average equipment costs of 0.06 USD per person served (data not shown). In addition, back-up power generators or batteries were often required. The costs of training (sponsored by the MfSW research program) also amounted to an average of 0.02 USD per person served (SI Table S7). Furthermore, to ensure comprehensive coverage of surveillance monitoring programs in rural areas, an inventory of all point water sources may be required. An analysis of national water point mapping exercises in eight African countries indicates that costs have an average of 0.14 USD per person served. $^{27}$ Overall, the start-up costs for laboratory equipment, staff training, and water point mapping would amount to 94452000 USD for all of sub-Saharan Africa (SI Text S3). For the 16 countries that reported their annual WASH budgets in the 2014 GLAAS report (Table 3), start-up costs would represent on average $3.1 \%$ (range: $0.1-8.7 \%$ ) of their annual WASH budgets (data not shown). These estimates suggest that start-up costs for microbial monitoring may be a more significant challenge at the national level than ongoing costs. In addition, we note that training can also be considered an ongoing cost, as periodic refreshers and training of new staff may be needed, resulting in an increase in the average cost per test (by $2.5 \pm 2.1 \mathrm{USD}$, or $12 \%$, see SI Table S7).

4.3. Beyond Water Quality Monitoring. In this study, we used the testing frequencies recommended in the WHO Guidelines as a benchmark to estimate monitoring costs because these guidelines underpin regulatory requirements for testing levels in a number of African countries (e.g., Burkina Faso, Guinea, Senegal, Ethiopia, and Kenya). ${ }^{7}$ However, it is important to recognize that meeting these monitoring requirements may not be sufficient to assess water safety. The likelihood that a limited amount of testing will provide an accurate measurement of microbial contamination is influenced by the actual contamination levels in the water source: among highly contaminated and uncontaminated sources, fewer water samples are needed to estimate actual contamination levels; however, among sources with fluctuating levels of contamination, many more samples are needed to estimate actual contamination levels. ${ }^{28,29}$ Therefore, testing strategies that account for water source contamination levels, rather than populations served may prove more useful for guiding water safety management. Nevertheless, the WHO Guidelines provide a starting point, and building monitoring programs that can meet these minimum requirements would pave the way for the future, where more strategic testing requirements may become increasingly realistic through increased in-country capacity, improved infrastructure, and lower per-test costs driven by economies of scale.

Finally, it is important to recognize that water quality monitoring can only help protect public health if immediate corrective actions (e.g., chlorine addition to a water system, water source closure, etc.) are taken when fecal contamination is detected. Such corrective actions require financial, human, and logistical resources, which implies that monitoring represents only a small fraction of the costs of water safety management.

4.4. Limitations. Although our cost-per-test estimate is based on actual data from monitoring institutions, our extrapolations to calculate national and regional costs are subject to uncertainties as they derive from a series of assumptions. However, our sensitivity analyses suggest that the order of magnitude of our overall cost estimate is robust. Despite this, it is possible that monitoring costs may, in practice, be higher than estimated in this study. First, it is likely that self-supply sources (e.g., private wells, rainwater harvesting) were omitted in national water point inventories. This would have led us to underestimate the testing costs. Second, some countries have established testing frequency requirements that are higher than the WHO recommendations (which we used for our estimates). ${ }^{7,14}$ Similarly, the testing frequency for point sources may increase as part of the efforts to track progress toward the SDGs. Third, our cost estimate only accounts for improved water sources, and therefore does not include $37 \%$ of the population of sub-Saharan Africa currently 
using unimproved sources. ${ }^{3}$ It is thus important to emphasize that the total expected monitoring costs will increase in the future as the number of people using improved sources increases. We note that JMP data, which are based on estimates from 2010 to 2014 (except for Somalia, where data were last collected in 2005), may already be an underestimate of the current coverage of improved water sources in sub-Saharan Africa. Conversely, our estimates assume that current testing typologies are representative of the near future. However, increasing applications of decentralized testing structures (i.e., water testing field kits deployed from local public health offices) in rural areas could lower logistics costs for monitoring remote point sources and potentially decrease overall monitoring costs. Finally, we note that our cost estimate for monitoring point sources is more uncertain than for piped sources, as illustrated by the sensitivity analysis.

4.5. Conclusions. As the SDGs brought renewed attention to the necessity of water quality measurements, our results indicate that in comparison to current WASH sector expenditures in sub-Saharan Africa, the costs of water quality monitoring programs are relatively small and should be prioritized in sector funding plans. However, it is important to note that starting up new monitoring programs can entail significant capital and staffing commitments, which may be hard to justify in small water systems that only have to conduct a small number of tests. Therefore, we propose that future research should investigate centralized testing facilities as a potential option to address monitoring needs in small towns and rural areas.

\section{ASSOCIATED CONTENT}

\section{S Supporting Information}

The Supporting Information is available free of charge on the ACS Publications website at DOI: 10.1021/acs.est.6b06442.

Detailed analyses of the number and size of piped water systems in eight countries, estimates of monitoring startup costs, and estimates of physicochemical testing costs are presented in the Supporting Information, along with supporting figures and tables referenced in the text (PDF)

\section{AUTHOR INFORMATION}

\section{Corresponding Author}

*Phone: +254 739-384-197; fax: +1 415-306-7594; e-mail: caroline@aquaya.org.

\section{ORCID}

Caroline Delaire: 0000-0001-8359-6847

Rachel Peletz: 0000-0002-9256-0800

Emily Kumpel: 0000-0003-0138-8441

Notes

The authors declare no competing financial interest.

\section{ACKNOWLEDGMENTS}

This work was supported by a grant from the Bill and Melinda Gates Foundation to The Aquaya Institute (Global Development Grant Number OPP1040691). We thank all the water suppliers and surveillance agencies that contributed to this study, as well as our former colleagues at The Aquaya Institute, Lola Aleru, Mateyo Bonham, and Bradley Lang, for their substantial help with data collection and cleaning. We thank Thanasius Sitolo (Ministry of Water, Malawi), Oscar Vivier
(Société des Eaux de Guinée, Guinea), and Mamadou Cellou Diallo (Service National d'Aménagement des Points d'Eau, Guinea) for providing datasets on water supplies.

\section{REFERENCES}

(1) Prüss-Ustün, A.; Bartram, J.; Clasen, T.; Colford, J. M.; Cumming, O.; Curtis, V.; Bonjour, S.; Dangour, A. D.; De France, J.; Fewtrell, L.; et al. Burden of disease from inadequate water, sanitation and hygiene in low- and middle-income settings: a retrospective analysis of data from 145 countries. Trop. Med. Int. Health 2014, 19 (8), 894-905.

(2) Prüss-Ustün, A.; Vickers, C.; Haefliger, P.; Bertollini, R. Knowns and unknowns on burden of disease due to chemicals: a systematic review. Environ. Health 2011, 10 (1), 9.

(3) WHO/UNICEF Joint Monitoring Programme. Progress on Sanitation and Drinking Water, 2015 Update and MDG Assessment.

(4) Bain, R.; Cronk, R.; Wright, J.; Yang, H.; Slaymaker, T.; Bartram, J. Fecal Contamination of Drinking-Water in Low- and MiddleIncome Countries: A Systematic Review and Meta-Analysis. PLoS Med. 2014, 11 (5), e1001644.

(5) Kumpel, E.; Peletz, R.; Bonham, M.; Khush, R. Assessing Drinking Water Quality and Water Safety Management in SubSaharan Africa Using Regulated Monitoring Data. Environ. Sci. Technol. 2016, 50 (20), 10869-10876.

(6) Rahman, Z.; Crocker, J.; Chang, K.; Khush, R.; Bartram, J. A comparative assessment of institutional frameworks for managing drinking water quality. J. Water, Sanit. Hyg. Dev. 2011, 1 (4), 242-258.

(7) Peletz, R.; Kumpel, E.; Bonham, M.; Rahman, Z.; Khush, R. To What Extent is Drinking Water Tested in Sub-Saharan Africa? A Comparative Analysis of Regulated Water Quality Monitoring. Int. J. Environ. Res. Public Health 2016, 13 (3), 275.

(8) Peletz, R.; Kisiangani, J.; Delaire, C.; Kumpel, E.; Bonham, M.; Ronoh, P.; Marks, S.; Khush, R. Why Do Water Quality Monitoring Programs Succeed or Fail? A Qualitative Comparative Analysis of Regulated Institutional Testing in sub-Saharan Africa (in preparation).

(9) USEPA. Water Quality Laboratory Capacity Building https:// www.usaid.gov/west-africa-regional/fact-sheets/usepa-water-qualitylaboratory-capacity-building (accessed November 4, 2016).

(10) Stauber, C.; Miller, C.; Cantrell, B.; Kroell, K. Evaluation of the compartment bag test for the detection of Escherichia coli in water. J. Microbiol. Methods 2014, 99, 66-70.

(11) Rahman, Z.; Khush, R.; Gundry, S. Aquatest: Expanding Microbial Water Quality Testing for Drinking Water Management. Drink. Water Saf. Int. 2010, 1 (4), 15-16.

(12) UNICEF. Real Time E. coli Detection https://www.unicef.org/ innovation/innovation_92771.html (accessed April 2, 2017).

(13) Bain, R.; Bartram, J.; Elliott, M.; Matthews, R.; McMahan, L.; Tung, R.; Chuang, P.; Gundry, S. A Summary Catalogue of Microbial Drinking Water Tests for Low and Medium Resource Settings. Int. J. Environ. Res. Public Health 2012, 9 (12), 1609-1625.

(14) Crocker, J.; Bartram, J. Comparison and Cost Analysis of Drinking Water Quality Monitoring Requirements versus Practice in Seven Developing Countries. Int. J. Environ. Res. Public Health 2014, 11 (7), 7333-7346.

(15) Oanda.com. Oanda.com www.oanda.com (accessed August 25, 2016).

(16) Bartram, J.; Ballance, R.; United Nations Environment Programme; World Health Organization. Water Quality Monitoring: A Practical Guide to the Design and Implementation of Freshwater Quality Studies and Monitoring Programmes; E \& FN Spon, 1996.

(17) Global Water. Water Quality Instrumentation Price List http:// www.globalw.com/catalog_wq.html (accessed November 7, 2016).

(18) WHO/UNICEF Joint Monitoring Programme for Water Supply and Sanitation. Country Files http://www.wssinfo.org/documents/ ?tx_displaycontroller[type]=country_files (accessed October 25, 2016).

(19) WHO. Guidelines for drinking-water quality, fourth edition; World Health Organization: Geneva, 2011. 
(20) UN Water Global Analysis and Assessment of Sanitation and Drinking Water. Investing in Water and Sanitation: Increasing Access, Reducing Inequalities; 2014.

(21) 3M. Petrifilm http://www.3m.com/3M/en_US/company-us/ all-3m-products/ /ECOLICT-3M-Petrifilm-E-coli-Coliform-CountPlates $\mathrm{N}=5002385+3293785155 \& \mathrm{rt}=$ rud (accessed November 4, 2016).

(22) IDEXX. Colilert https://www.idexx.com/water/products/ colilert.html (accessed November 4, 2016).

(23) Baumann, E.; Montangero, A.; Sutton, S.; Erpf, K. WASH Technology Information Packages; 2010.

(24) Wright, J.; Liu, J.; Bain, R.; Perez, A.; Crocker, J.; Bartram, J.; Gundry, S. Water quality laboratories in Colombia: A GIS-based study of urban and rural accessibility. Sci. Total Environ. 2014, 485-486, $643-652$.

(25) United Nations Population Division. World Urbanization Prospects, the 2014 revision https://esa.un.org/unpd/wup/CDROM/ (accessed December 19, 2016).

(26) Hutton, G.; Varughese, M. The Costs of Meeting the 2030 Sustainable Development Goal Targets on Drinking Water, Sanitation, and Hygiene - Summary Report. 2016, No. January 2016.

(27) Personal communication with Ellen Greggio from WaterAid on $09 / 14 / 2106$.

(28) Taylor, D. D. J.; Khush, R; Peletz, R.; Kumpel, E. Efficacy of Microbial Sampling Recommendations in Low-Resource Settings. Prep.

(29) Ellis, J. Handbook on the Design and Interpretation of Monitoring Programmes, volume Technical Report NS29; Water Research Centre, Medmenham, United Kingdom, 1989.

(30) Société des Eaux de Guinée. Taux de Racordement au 31/12/ 2013 sur la base du ressencement de la population de 1996; 2013.

(31) Service National d'Aménagement des Points d'Eau. Liste générale des AEP rurales (situation et données techniques); 2014.

(32) Water Services Regulatory Board. Impact Report Issue no. 8 (2013-2014) http://www.wasreb.go.ke/impact-reports (accessed November 7,2016$)$.

(33) International Finance Corporation. The Market For Small-Scale Piped Water Systems In Kenya; 2012.

(34) Kenya Open Data. Household Access to Water by Sublocation (2009) https://www.opendata.go.ke/Water/Housheold-Access-ToWater-By-Sublocation-2009/g3dc-dk7w (accessed November 7, 2016).

(35) Kenya Open Data. Population, Households and Density by Sublocation (2009) https://www.opendata.go.ke/Population/CensusVolume-1-Question-1-Population-Households-a/wd27-eki2 (accessed November 7, 2016).

(36) Central Water Authority. Annual Report 2014 http://cwa. govmu.org/Documents /AnnualReport/Annualreport2014/ CWAAnnualReport2014LRpart3.pdf (accessed November 7, 2016).

(37) Conselho de Regulacao do Abastecimento de Agua. 2009-2014 Retrospective Report http://www.cra.org.mz/pdf/ RETROSPECTIVEREPORT2009-2014-Engversion.pdf (accessed November 7, 2016).

(38) Instituto Nacional de Estatistica. Recenseamento Geral da População e Habitação 2007 http://www.ine.gov.mz/operacoesestatisticas/censos/censo-2007/rgph-2007 (accessed November 7, 2016).

(39) Blue Drop. Report 2012 https://www.dwa.gov.za/dir_ws/ DWQR/Default.asp?Pageid=6\&SearchString=Report (accessed ${ }^{-}$November 7,2016 ).

(40) Energy and Water Utilities Regulatory Authority. Water Regional and District Reports 2014-2015 zhttp://144.76.33.232/ ?page_id=1109 (accessed November 7, 2016).

(41) Ministry of Water and Environment. Uganda Water Supply Atlas (2014-2015) http://www.wateruganda.com/ (accessed November 7,2016$)$.

(42) National Water Supply and Sanitation Council. Urban and PeriUrban Water Supply and Sanitation Sector Report 2015 http://www. nwasco.org.zm/jdownloads/Publications/Urban\%20and\%20Peri-
Urban\%20WSS\%20Sector\%20Reports/sectorreport2015small.pdf (accessed November 7, 2016).

(43) Eau Rurale Benin (2014). Ouvrages http://eaururalebenin.org/ donnees/ouvrages/ (accessed November 7, 2016).

(44) Community Water and Sanitation Agency. National Coverage Statistics-Potable Water (Community Based Water Systems, 2014) h t t p : / / w w w. c w s a.gov.g h/down load s / 2014\%20Rural\%20Coverage\%20Statistics2.pdf (accessed November 7, 2016).

(45) mWater (2016). Portal https://portal.mwater.co/\#/entities (accessed November 7, 2016).

(46) Kenya Open Data. Type of Water Sources (2013) https://www. opendata.go.ke/Water-and-Sanitation/Types-of-Water-Source-Pointsin-Kisumu-County/mdxx-ptyp (accessed November 7, 2016).

(47) Ministry of Health. Liberia Water Point Atlas (2011) http:// wash-liberia.org/wp-content/blogs.dir/6/files/sites/6/2013/01/ Final_Review_Version_-Waterpoint_Atlas_Investment_Plan_x1. pdf (accessed November 7, 2016).

(48) Ministry of Agriculture Water Development and Irrigation. Malawi Rural Water Supply Investment Plan 2014-2020; 2015.

(49) Programme d'Eau Potable et d'Assainissement du Millénaire. Infrastructures hydrauliques pour l'eau potable en milieu rural (2016) http://www.pepam.gouv.sn/infrastructure.php?rubr=inf (accessed November 7,2016 ).

(50) Ministry of Energy and Water Resources. Sierra Leone Water Point Report (2012) http://www.rural-water-supply.net/ ressources/ documents/default/1-640-2-1416492226.pdf (accessed November 7, 2016).

(51) Ministry of Water. Water Point Mapping Tanzania (2014) http://wpm.maji.go.tz/ (accessed November 7, 2016). 